\title{
The effect of insulator geometrical profile on electric field distributions
}

\author{
Ali. A. Salem ${ }^{1}$, R. Abd-Rahman', M. S. Kamarudin ${ }^{3}$, H. Ahmed ${ }^{4}$, N.A.M. Jamail ${ }^{5}$, N.A. Othman ${ }^{6}$, \\ M.F.M. Yousof ${ }^{7}$, M. T. Ishak ${ }^{8}$, S. Al-Ameri ${ }^{9}$ \\ ${ }_{1,2,3,4,5,6,7,9}$ Faculty Electrical and Electronic Engineering, University Tun Hussein Onn Malaysia (UTHM), Malaysia \\ ${ }^{8}$ Faculty of Engineering, National Defence University of Malaysia (UPNM), Malaysia
}

\begin{tabular}{l}
\hline Article Info \\
\hline Article history: \\
Received Oct 1, 2018 \\
Revised Dec 10, 2018 \\
Accepted Jan 25, 2019 \\
\hline Keywords: \\
Electric field \\
Electrical potential \\
Finite element method (FEM) \\
Insulator geometry profile \\
Polymeric insulator
\end{tabular}

\begin{abstract}
In recent years, silicone rubber (SIR) insulators are use widely on high voltage transmission lines, particularly in heavy polluted environment. The performance of SIR in highly dependent on electric field profile that may lead to other serious problem such as ageing and flashover phenomenon. In this paper, electric field and potential distribution around insulator profile were computed using finite element method approach. Insulator geometrical profile i.e. shed radius, inclination angle, width and length has been varied and analyzed. Simulation results reveal that electric field is greatest at area near to the ground and high voltage terminal. Several recommendations have been proposed on insulator profile in achieving optimized electrical performance of the insulator.
\end{abstract}

Copyright $@ 2019$ Institute of Advanced Engineering and Science. All rights reserved.

\section{Corresponding Author:}

Ali Ahmed Ali Salem,

Department of Electrical and Electronic Engineering,

University Tun Hussein Onn Malaysia,

86400 Parit Raja, Johor, Malaysia.

Email: en.alisalem@gmail.com

\section{INTRODUCTION}

Through of stages of delivery electrical power, which are the generation, transmission and distribution systems using overhead lines the isolation system exposed to many stresses electrical, mechanical and environmental stress. A reliability of power system might be disrupted by reinforcement of electric field along of the insulators [1]. Damage to the outdoor electrical insulators resulting of the electrical fields could be increased especially near to electrodes exponentially with time [2], [3].

The Silicone rubber insulators have some of the characteristics better than some insulators such as hydrophobicity, possess higher impact strength, and compact design, so their application on power transmission system tends to increase rapidly. Electric fields distribution, observed on insulators used in overhead lines, are the most important issue for distribution systems [2]. Field stress is a complex issue due to diverse reason such as different contaminations, a shape of insulators, and different stresses on the insulator and unknown impact of moisture on the contaminations [4]. The efficiency of insulators under different stresses could be tested by analysis of electrical field on their surface. On the other hand, the field stress on insulators can cause power failure at a very far distance. The field stress on insulators is still a damage threat to the safe process of a power distribution system, which might led to occur of flashover [3]. It is generally believed that electric field is becoming ever more critical to investigate the performance of high voltage insulators [5].

In this article, the electric field using 3D finite element method (FEM) using COMSOL Multiphysics 2.5 software based on replacement and modify of insulators profile along a standard $11 \mathrm{kV}$ silicone rubber insulator has been computed. This studying took to account inclination of angle $\theta$, shed radius 
$\mathrm{R}$, shed length $\mathrm{LSH}$, and distance from shed to ground terminal $\mathrm{L}$ on the $11 \mathrm{kV}$ silicon rubber insulator Moreover, a suitable solution to reduce of electric field were suggested. This can be considered as an approach to enhance \& optimized the insulation performance, similar to other dielectric materials i.e. gases and liquid, where researchers try to find best possible candidate as for an alternative [6], [7].

\section{MATHEMATICAL CHARACTERIZATION}

\subsection{Calculate of E-Field and Potential Voltage Distribution}

One easy method for field stress determination on insulators surfaces is determine voltage distribution [4]. Then, the E-field distribution is calculated by minus gradient of voltage distribution. In electrostatic field case, E-field distribution can be defined as follows [5]:

$$
E=-\nabla V
$$

Based on Maxwell's equation,

$$
\nabla E=\rho / \varepsilon
$$

Where $\mathrm{E}$ is the electric field, V Apply voltage, $\rho$ Resistivity $\Omega / \mathrm{m}$ and $\varepsilon$ Material permittivity

According to relative permittivity ( $\varepsilon r$ ), the isotropic material was classified. Relative permittivity or dielectric constant $(\varepsilon r)$ linked the material permittivity $(\varepsilon)$ with the permittivity of vacuum $(\varepsilon 0)$ as the following equation:

$$
\varepsilon=\varepsilon_{r} \varepsilon_{0}, \varepsilon_{0}=8.85 \times 10^{-12}
$$

For obtaining Poisson Equation place (1) to (2)

$$
\varepsilon \nabla^{2} \mathrm{~V}=-\rho
$$

As shows in (4) becomes Laplace equation when $\rho=0$ as follows:

$$
\varepsilon \nabla^{2} V=0
$$

\subsection{Analysis of Finite Element Method (FEM)}

Many software like ANSYS, ADINA, LS-DYNA, and COSMOL Multiphysics 5.2 use FEM to compute of structures properties, three stages in each FEM processing are pre-processing and manipulation of data, compute of FEM case, and post-processing of final results. FEM has been vastly used in electric, magnetic, and thermal application as well as hydraulic applications since the late1970s [8].

Assuming that the area under research does not include charges for any space and surface. The 2D functional $\mathrm{F}(\mathrm{u})$ in the coordinates Cartesian system as in Figure 1 can be expressed as follows [9]:

$$
F(u)=\frac{1}{2} \int_{S}\left[\varepsilon_{x}\left(\frac{d u}{d x}\right)^{2}+\varepsilon_{y}\left(\frac{d u}{d y}\right)^{2}\right] d x d y
$$

Where $\varepsilon_{x}$ is X-Components of material permittivity, $\varepsilon_{y}$ is Y-Components of material permittivity in the and $\mathrm{u}=$ Potential voltage.

In the isotropic permittivity case $\left(\varepsilon=\varepsilon_{x}=\varepsilon_{y}\right)$ and

$$
F(u)=\frac{1}{2} \int_{S} \varepsilon\left[\left(\frac{d u}{d x}\right)^{2}+\left(\frac{d u}{d y}\right)^{2}\right] d x d y
$$

If influence dielectric loss on the distribution of electric field took to account, the complex function $\mathrm{F}(\mathrm{u})$ should be written as

$$
F(u)^{*}=\frac{1}{2} \int_{S} \omega \varepsilon_{0}(\varepsilon-j \varepsilon \operatorname{tg} \delta)\left[\left(\frac{d u^{*}}{d x}\right)^{2}+\left(\frac{d u^{*}}{d y}\right)^{2}\right] d x d y
$$


Where $\omega$ is angular frequency, $\operatorname{tg} \delta=$ the tangent of the insulator loss angle and $\mathrm{u}^{*}$ is the complex potential voltage. Assuming there is linear diversity of the voltage in each sub-domain Se.

$$
u_{e}(x, y)=\alpha_{e 1}+\alpha_{e 2} x+\alpha_{e 3} y ;(\mathrm{e}=1,2,3, \ldots . . \mathrm{ne})
$$

Where is $\alpha_{e 1}$ is coefficients of computational for element e1, $\alpha_{e 2}$ coefficients of computational for element $\mathrm{e} 2, \alpha_{e 3}$ coefficients of computational for element $\mathrm{e} 3, u_{e}(x, y)$ potential voltage of any arbitrary dot inside each sub-domain $\mathrm{Se}$ and $\mathrm{Se}$ is number of elements of triangle. The electric potential at the node in the network can be calculated by the following function $\mathrm{F}(\mathrm{u})$, that is:

$$
\frac{\partial F\left(u_{i}\right)}{\partial u_{i}}=0 ; i=1,2, \ldots . n p
$$

Where $\mathrm{np}$ is stands for the total number of nodes in the network.

\section{CHARACTERIZATION FOR MODEL}

\subsection{Properties and Materials of the Model Insulator}

Four sheds $11 \mathrm{kV}$ polymeric (silicone rubber SIR) insulator was selected to compute of the electric field and potential voltage distribution. The polymeric insulator made up of three main materials as illustrated in Figure. 1:(i) Loadbearing and insulating material a fibre reinforced plastic (FRP) as the rod, (ii) Insulating material silicone rubber as weather sheds that cover the to protect it from the vandalism(Polymeric Housing), (iii) Loadbearing material metal end fittings that made of forged steel to withstand the mechanical stress [10], [11]. The dimensions of insulator that showed in Figure 1 are presented in Table 1.

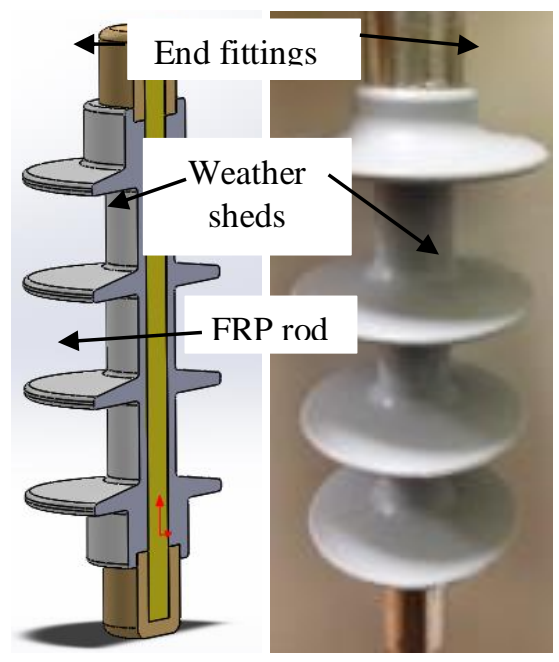

Figure 1. An 11kV SIR insulator under study:(a) A 3D insulator model, and (b) practical insulator

\begin{tabular}{cc} 
Table 1. Details the Dimensions of Insulator \\
Parameter & Length in $(\mathrm{mm})$ \\
\hline Creepage distance & 375 \\
End fitting separation & 175 \\
Core diameter & 18 \\
Diameter of trunk & 28 \\
Diameter of shed & 90 \\
Separation of shed & 46 \\
\hline
\end{tabular}

The properties of material selected for modelling of insulator in this research are demonstrated in Table 2 [10]. 
Table 2 Properties of Material for Modelling of Insulator

\begin{tabular}{ccc}
\hline Material & Relative Permittivity, $\varepsilon_{\mathrm{r}}$ & Conductivity, $\sigma(\mu \mathrm{S} / \mathrm{m})$ \\
\hline FRP core & 7.1 & $0.1 \times 10^{-8}$ \\
SIR & 4.3 & $0.1 \times 10^{-8}$ \\
Forged steel & 1 & $5.9 \times 10^{13}$ \\
Layer of pollution & 80 & 0.6 \\
Air & 1 & $0.1 \times 10^{-9}$ \\
\hline
\end{tabular}

\subsection{Geometry and Physics of Insulator}

An eleven $\mathrm{kV}$ at $50 \mathrm{~Hz}$ is energized on the upper terminal while the lower terminal connected directly to the ground $(0 \mathrm{kV})$. The material properties as was mentioned before having applied to the domains of the Three-dimensions of the silicone rubber insulator for FEM simulation using COMSOL Multiphysics 5.2 software as illustrated in Figure 2(a) [13], [14]. To boost simulation accuracy the mesh element along the leakage distance of the insulator will refine manually [12], [15]. The insulator and its surrounding air medium represented in Figure 2b.

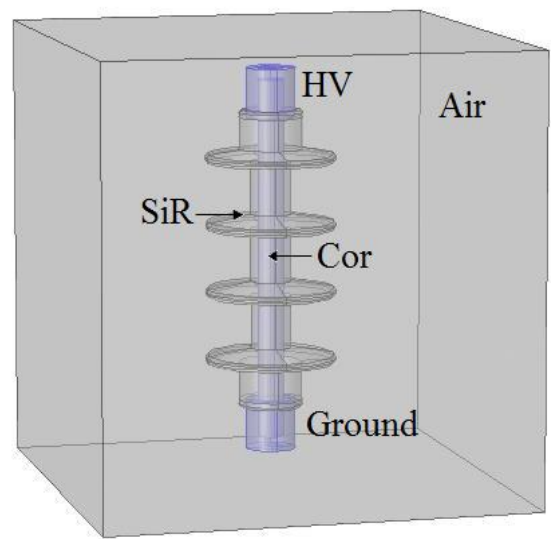

(a)

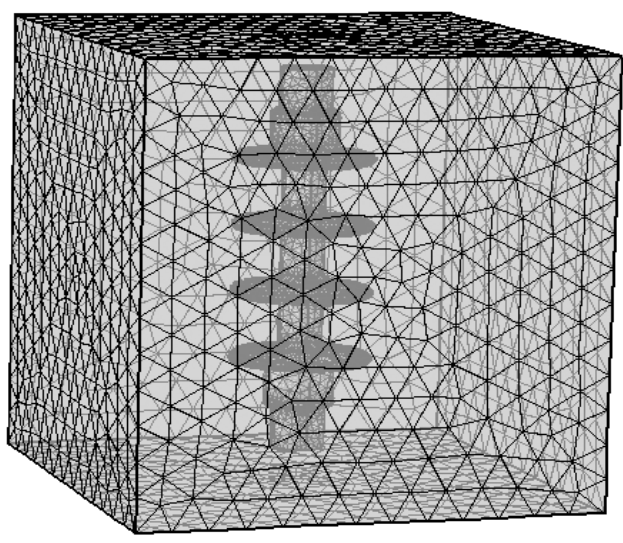

(b)

Figure 2. (a) A 3D SIR insulator model in pre-simulation (b) Meshed model

\section{SIMULATION OF THE MODEL}

The electrostatic formulation of AC/DC physics was used for all simulations. Effect of variation of shed radius at $\mathrm{R}=5,10$, and $15 \mathrm{~mm}$ ), shed's inclination angle at $\theta=5,10$, and $15 \mathrm{~mm}$, shed's length at Lsh $=$ 45,65 , and $85 \mathrm{~mm}$, diameter of core at $\mathrm{r}=28,33$, and 38 , and distance from the shed to the end fitting at $\mathrm{H}=$ 20, 30, and $40 \mathrm{~mm}$ proposed on the electric field and electric potential distribution has studied in detail as showed in Figure 3.
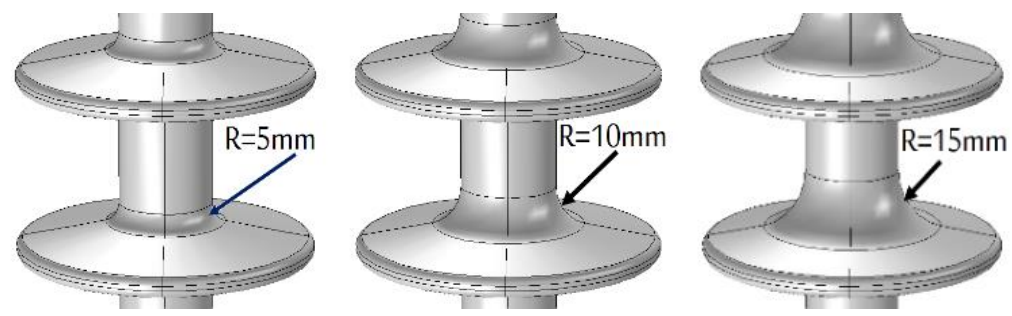

I II III

(a) Change of the shed radius 

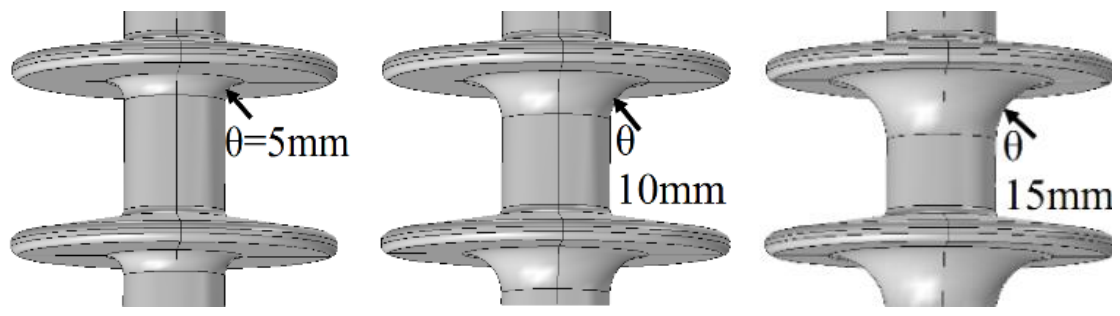

I II III

(b) Change of the shed's inclination angle diameter
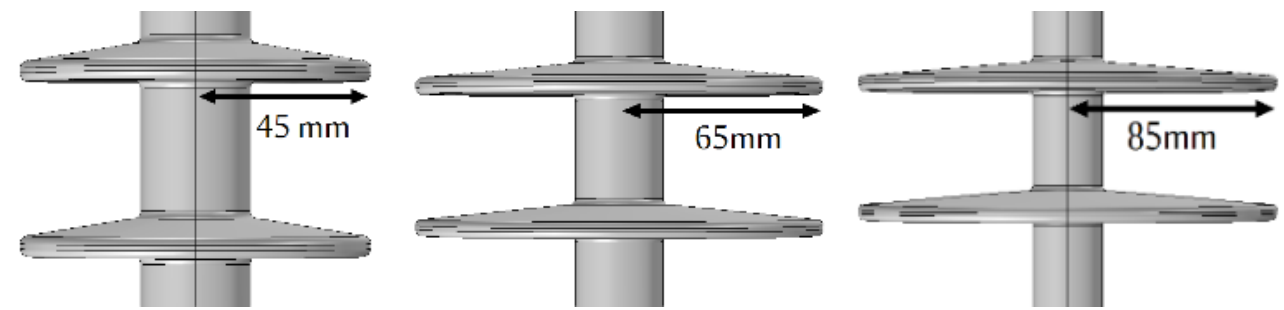

I II III

(c) Change of the shed length
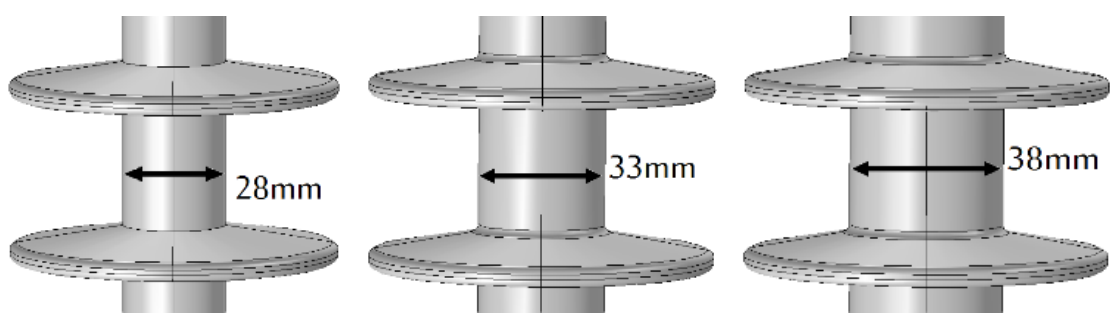

I II III

(d) Change of core diameter
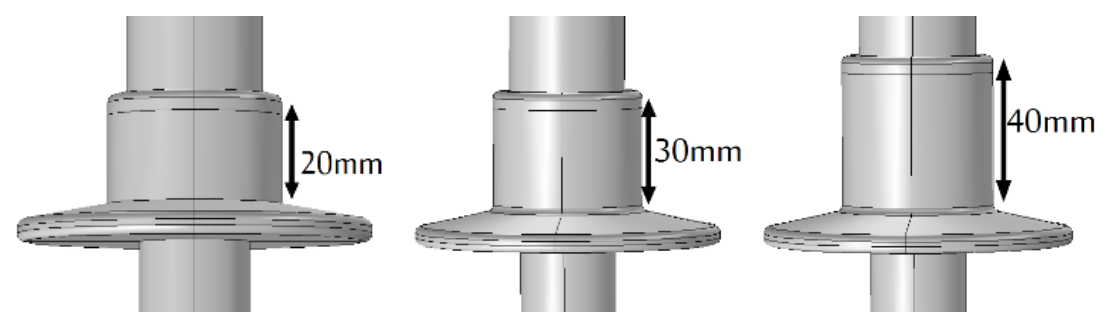

I II III

(e) Change of fitting distance

Figure 3. The proposed profiles for SiR insulator in clean and pollution conditions

\section{RESULT OF SIMULATION}

Potential voltage and electrical field distribution in the $11-\mathrm{kV}$ clean polymeric insulator in the normal case is presented in Figure 5. In the condition of the clean insulator, a small current called as displacement current is flowing over the surface. According to the self-capacitance, the voltage for a clean insulator surface is distributed.

\subsection{Effect of Change of the Shed's Radius}

Electric Potential and electric field distribution along silicon rubber insulator is shown in Figure 4(b). The shed's radius on the insulator was varied to simulate and study its effect in electric potential and field. 
A slight change in the electric field and potential in the surround of ground electrode region of the dielectric while in the surround of high voltage area the field intensity and voltage increase with the increase of the shed's radius as demonstrated in Figure 5.

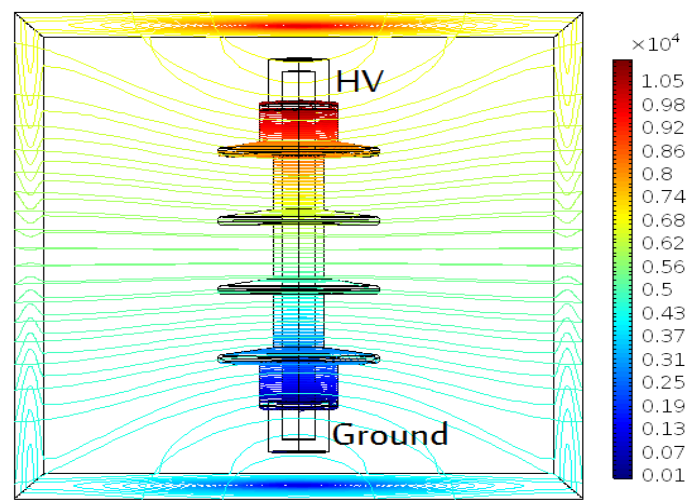

(a)

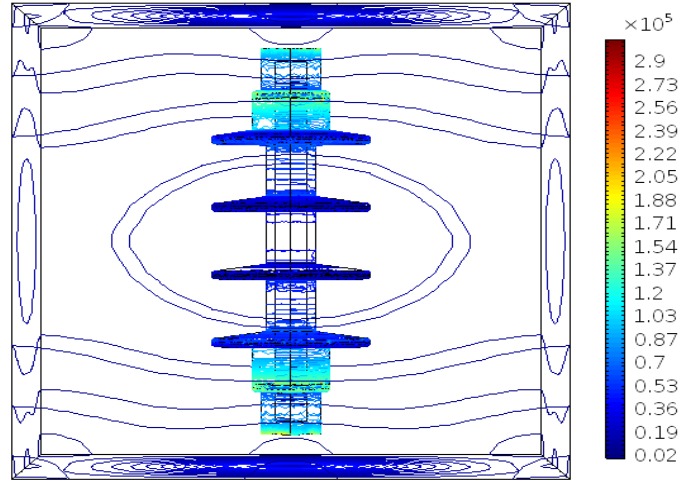

(b)

Figure 4. (a) Electric potential and (b) Electric field distribution under clean condition

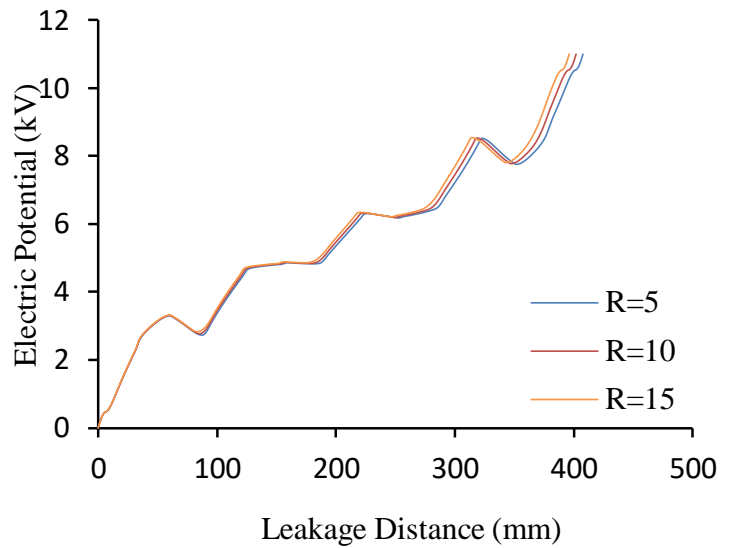

(a)

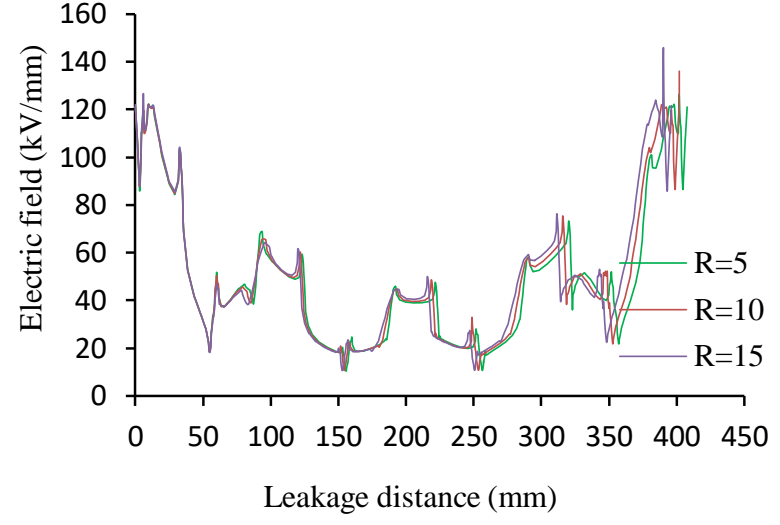

(b)

Figure 5. (a) Electric potential and (b) Electric field with different shed's radius

\subsection{Effect of Change of the Shed's Inclination Angle Diameter}

The shed's inclination angle diameter of the $11 \mathrm{kV}$ RIS insulator under study is $5 \mathrm{~mm}$ as shown in above Figure 3(b). The parameter is varied with values of 5, 10 and 15 to study the effects of the electric field stress. The electric potential and electric field stress along the surface of the insulator is shown in Figure 6.

The increase of electric field stress and the voltage near to the electrodes with the increase of the shed's inclination angle diameter were observed. Conversely, in the middle of the insulator, the electrical potential and field tend to decrease with the increase of the shed's inclination angle diameter as can be seen in Figure 6. The electric field has seemed smoother with increase the shed's radius as shown in Figure 5 and the inclination angle diameter as shown in Figure 6. 


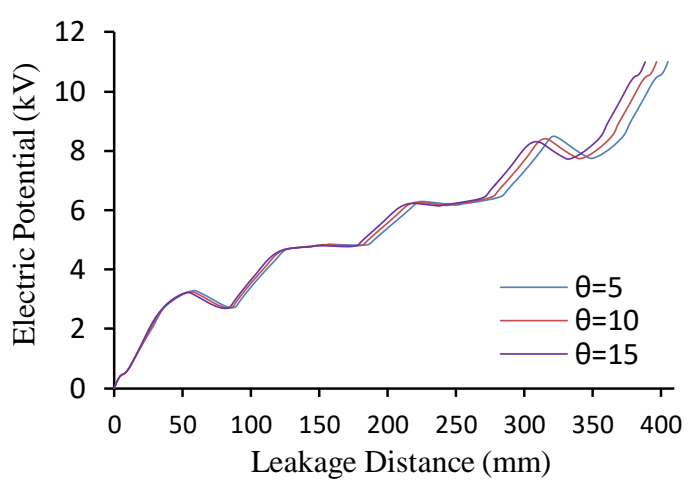

(a)

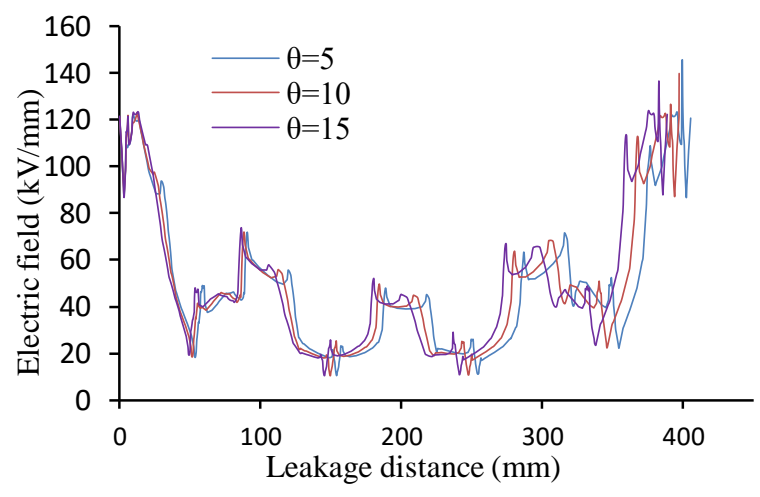

(b)

Figure 6. (a) Electric potential and (b) Electric field, with different inclination angle

\subsection{Effects of the Shed's Diameter}

The shed's diameter of the $11 \mathrm{kV}$ polymeric insulator under study is $90 \mathrm{~mm}$ as shown in Figure 3(c). The parameter is varied with values of $90 \mathrm{~mm}, 130 \mathrm{~mm}$, and $170 \mathrm{~mm}$ to observe the effects of the electric field stress. The electric field stress and potential voltage along the surface of the insulator are shown in Figure 4. From Figure 7, it is comprehended that at the largest shed's diameter generally yields the highest voltage and electric field stress [12]. However, at first shed's outer corner, the electric field stress decreases as the shed's diameter increases.

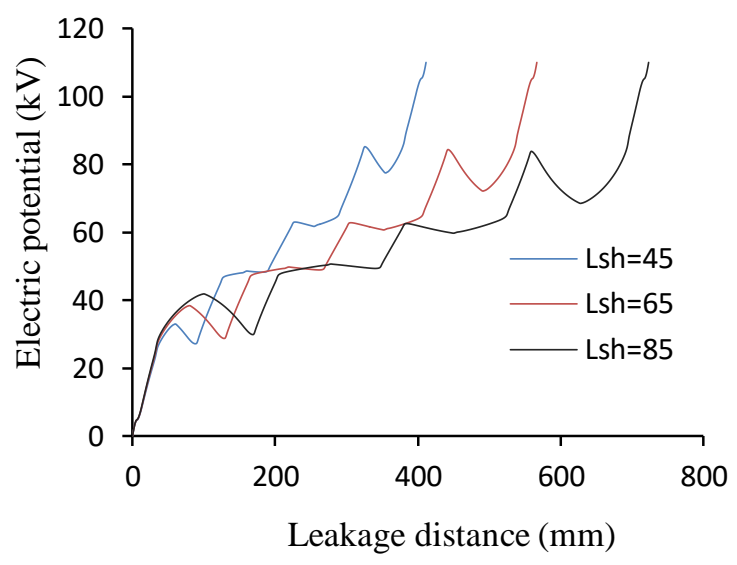

(a)

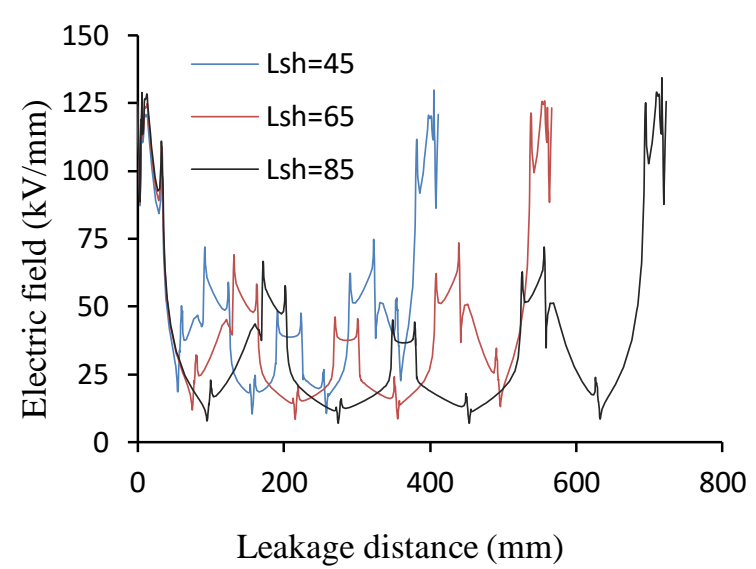

(b)

Figure 7. (a) Electric potential and (b) electric field, with different shed's diameter

\subsection{Effects of the Core Diameter}

The electric potential distribution in this case has negligible changes as compared to other cases as illustrated in Figure 8(a). Electric field near to electrodes decreases with increasing core diameter while in the middle of the insulator the electric field tends to increase with increasing diameter of core insulator as shown in Figure 8(b). 


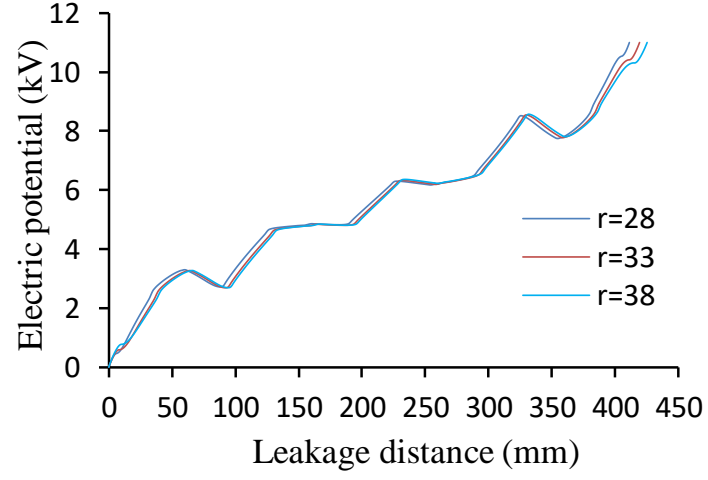

(a)

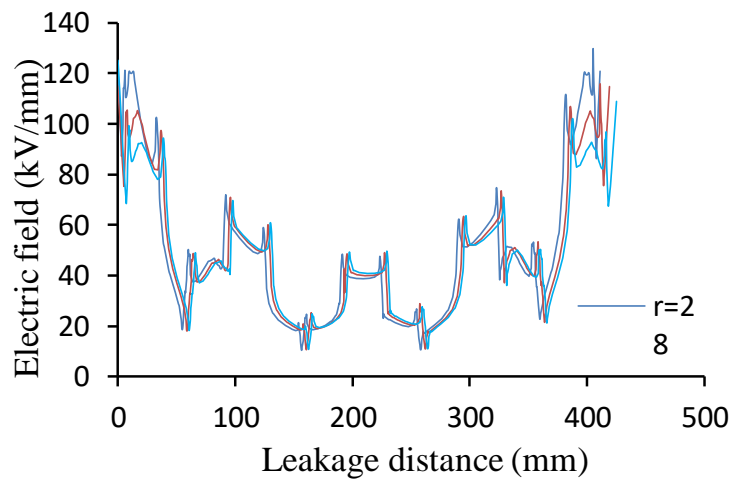

(b)

Figure 8. (a) Electric potential and (b) Electric field, with different core diameter

\subsection{Effects of the Distance Between the First Shed and End Fitting}

From Figure 9 it is comprehended that the highest distance between the first shed and the bottom end fitting generally yields a lower electric field stress and potential voltage while the shortest distance gives the highest increment in electric field stress and voltage as well as. Hence, it can be concluded from Figure 9(b) that as the distance between the first shed and the bottom end fitting increases, the electric field stress at first shed decreased.

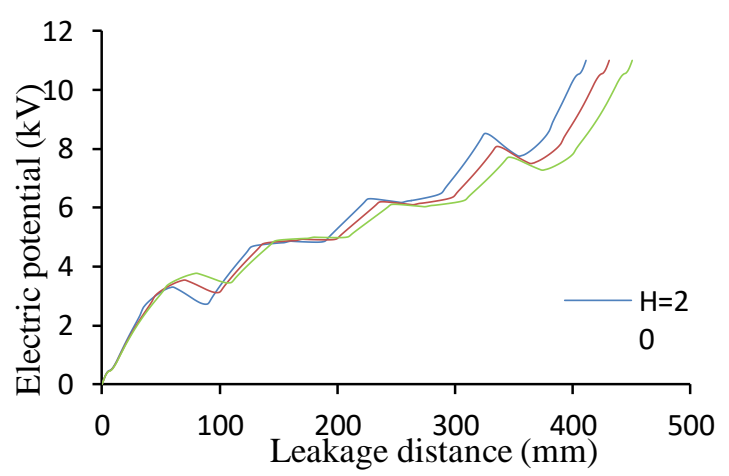

(a)

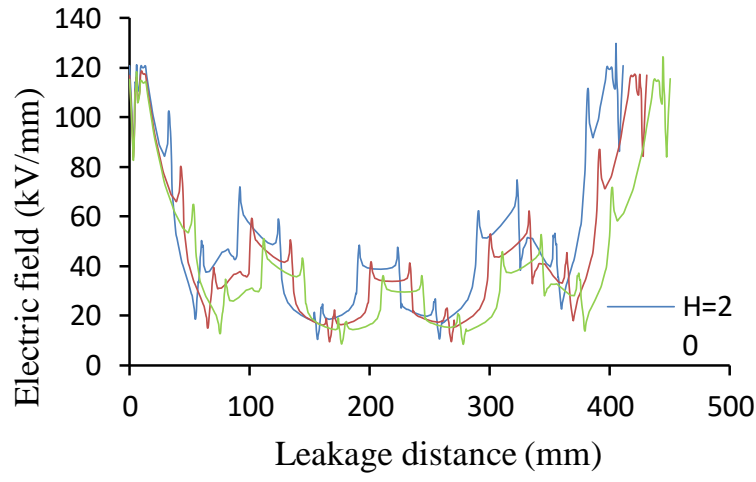

(b)

Figure 9. (a) Electric potential and (b) Electric field, with different distance between the first shed and end fitting

\section{CONCLUSION}

Computation of electric field and potential distribution were carried out to study the effects of the various profiles on the silicone rubber insulator. The electric field stress and potential voltage along the polymeric insulator were highly non-uniform due to the shape of the insulator. The sharp edges of the insulator tend to have higher electric field stress on the insulator's surface while the smooth edges have lower electric field stress. Several design considerations were studied to observe the effects to the electric field stress and electric potential. The design of the end fittings showed the significant change in the electric field stress. End fittings with round edges tend to reduce the electric field stress along the insulator's surface as well as increasing the distance from sheds to electrodes.

\section{ACKNOWLEDGEMENTS}

The authors would like to thank University Tun Hussein Onn Malaysia and the office for Research, Innovation, Commercialization, and consultancy Management (ORICC) for funding this research under the postgraduate Research Grant (GPPS), VOT \#U711. 


\section{REFERENCES}

[1] I. Ahmadi-Joneidi, A. Majzoobi, A. A. Shayegani, H. Mohseni, J. Jadidian, "Aging Evaluation of Silicone rubber insulators using leakage current and flashover voltage analysis", IEEE Transactions on Dielectrics and Electrical Insulation, Vol. 20, No. 1, Page(s): 212 - 220, 2013.

[2] R. Abd-Rahman, A. Haddad, N. Harid, and Griffiths, "Stress control on polymeric outdoor insulators using Zinc oxide microvaristor composites," IEEE Trans. Dielectr. Electr. Insul., vol. 19, no. 2, pp. 705-713, 2012.

[3] Ali. A. Salem, "A Review of the Dynamic Modelling of Pollution Flashover on High Voltage Outdoor Insulators," J. Phys. Conf. Ser., vol. 1049, 2018.

[4] Ali. A. Salem; R. Abd Rahman; M. S. Kamarudin; N. A. Othman "Factors and models of pollution flashover on high voltage outdoor insulators: Review” 2017 IEEE Conference on Energy Conversion (CENCON).241-246,2017.

[5] A. P. and R. A.-R. M. S. Kamarudin*, N. H. Radzi, "IET Conferences," in Simulation of electric field properties for air breakdown using COMSOL multiphysics, 2016, pp. 1-5.

[6] M. S. Kamarudin et al., "Purpose-built test rig for gas insulation breakdown tests under lightning impulse," PECON 2016 - 2016 IEEE 6th Int. Conf. Power Energy, Conf. Proceeding, pp. 333-337, 2017.

[7] Z. Farhadinejad, M. Ehsani, I. Ahmadi- Joneidi, A. A. Shayegani, H. Mohseni, "An investigation of the effect of UVC radiation on thermal, electrical properties and morphological behavior of silicone rubber insulators" IEEE Transactions on Dielectrics and Electrical Insulation, Vol. 19, No. 5, Page(s): 1740- 1749, October 2012.

[8] M. Farzaneh, Outdoor insulators: overview of in-service experience, inspection practice and future challenges, IEEE Electrical Insulation Conference, pp. 542 - 550, 2009.

[9] Joneidi, I. A., Kamarposhti, M. A., Akmal, A. A. S., \& Mohseni, H. (2013). Leakage current analysis, FFT calculation and electric field distribution under water droplet on polluted silicon rubber insulator. Electrical Engineering, 95(4), 315-323.

[10] A. Haddad, M. S. Kamarudin, and M. F. M. Yousof, "Dynamic Modelling of Polluted Outdoor Insulator under Wet Weather Conditions," pp. 610-614, 2016.

[11] B.marungsri,W.onchantuek,andA.onsivilai "Electric Filed and Potential Distribution along Surface of Silicon Rubber Polymer Insulators Using Finite Element Method" International Journal of Electrical and Electronics Engineering 3:10 2009.

[12] B. Marungsri, W. Onchantuek, A. Oonsivilai and T.Kulworawanichpong "Analysis of electric Field and Potential Distributions along Surface of Silicone Rubber Insulators under contamination Conditions Using Finite Element Method" World Academy of Science, Engineering and Technology.

[13] Rifai, R. A., Mansour, A. H. \& Ahmed, M. A. H. (2015). Estimation of the electric field and potential distribution on three dimension model of polymeric insulator using finite element method

[14] COMSOL, "Introduction to COMSOL Multiphysics", May 2013.

[15] Schumann, U. et al, "FEM Calculation and Measurement of the Electrical Field Distribution of HV Composite Insulator Arrangements", 39th CIGRE Session, August 2002.

\section{BIOGRAPHIES OF AUTHORS}

Ali Ahmed Ali Salem (Ali. A. Salem) was born in Sana'a, Yemen on March 1,1985.
He received M.Eng. in Electrical Power Engineering from Universiti Tun Hussein Onn
Malaysia (UTHM) from 2014 to 2016. Currently he is Pursuing Ph.D. degree at High Voltage
in Faculty of Electrical Engineering, UTHM. His research interest includes the dynamic arc
modelling of pollution flashover on high voltage outdoor insulators.

Indonesian J Elec Eng \& Comp Sci, Vol. 14, No. 2, May 2019 : 618 - 627 


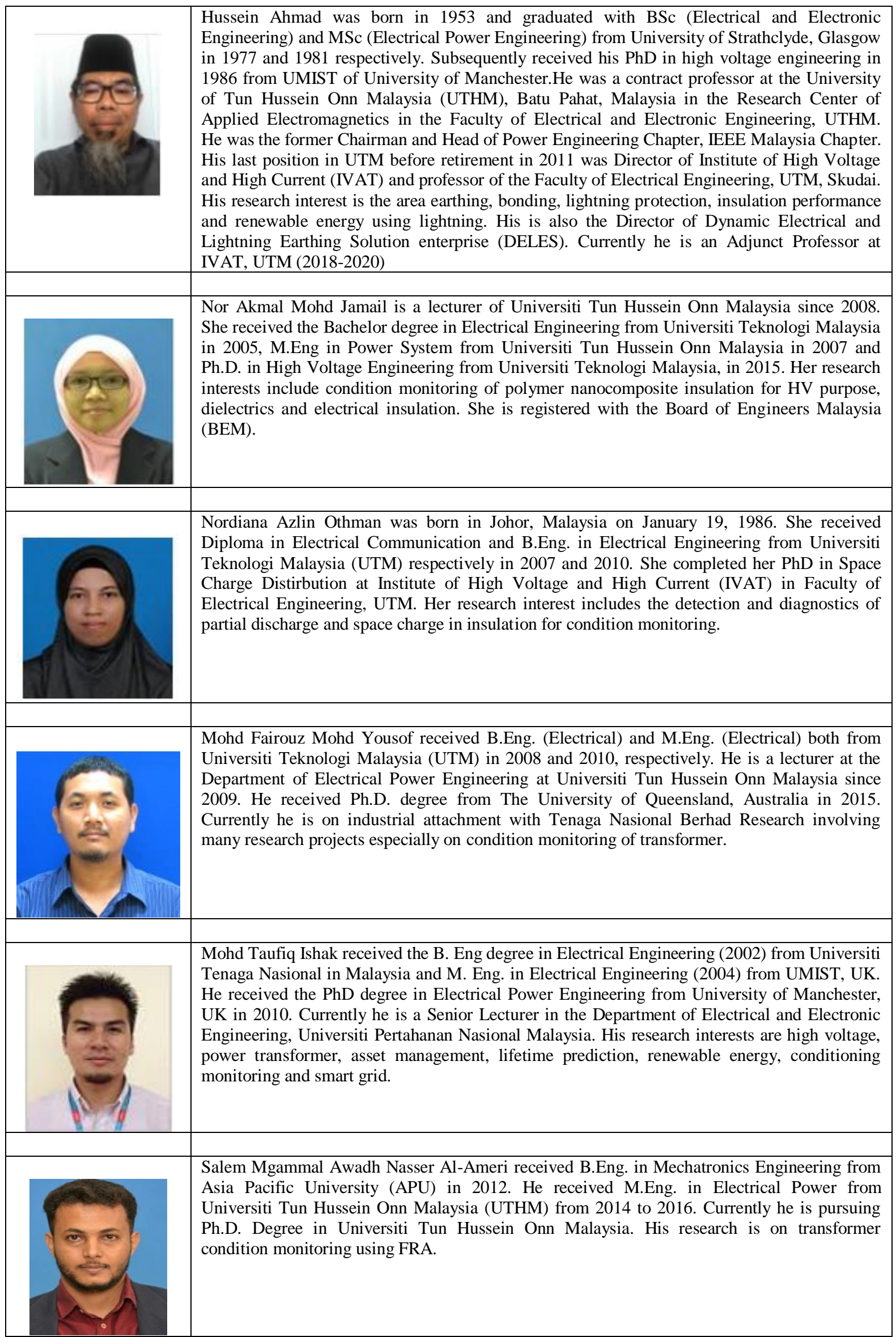

